\title{
México-La Habana-Madrid: Adolfo Sánchez Vázquez en el eje transatlántico de la guerra fría
}

\section{Mexico-Havana-Madrid: Adolfo Sánchez Vázquez on the Transatlantic Axis of the Cold War}

Artículo recibido el I8 de mayo de 2017; devuelto para revisión el 2 de agosto de 20I7; aceptado el 5 de diciembre de 20I7, http://dx.doi.org/IO.2220I/iie.I8703062e.20I8.II2.2627

Jaime Vindel Universidad Complutense de Madrid-Departamento de Historia del Arte, España, javindel@ucm.es

Líneas de investigación

Lines of research

Publicaciones más relevantes
Arte, política y movimientos sociales; estética y Marxismo; estudios culturales y ecología.

Art, politics and social movements; aesthetics and Marxism; cultural studies and ecology.

Transparente opacidad. Arte conceptual en los limites del lenguaje y la politica (Madrid: Brumaria, 2015 [ $2^{\mathrm{a}}$ ed. corregida y ampliada, 2016]); en coautoría con Graciela Carnevale, Marcelo Expósito, André Mesquita, Desinventario. Esquirlas de Tucumán Arde en el Archivo Graciela Carnevale (Santiago de Chile y Madrid: Ocholibros/Museo Nacional Centro de Arte Reina Sofía, 20I5); La vida por asalto: arte, politica e historia en Argentina entre 1965 y 2001 (Madrid: Brumaria, 2014); editor junto con Jesús Carrillo de Desacuerdos 8: Crítica (Barcelona y Madrid: Museo de Arte Contemporáneo de Barcelona/Museo Nacional Centro de Arte Reina Sofía, 20I4); coautor y editor de Perder la forma humana. Una imagen sismica de los años ochenta en América Latina (Madrid: Museo Nacional Centro de Arte Reina Sofía, 20I2).

Resumen Este artículo analiza la actividad intelectual del filósofo hispano-mexicano Adolfo Sánchez Vázquez en el eje transatlántico de la cultura comunista de la guerra fría. A partir del trabajo con documentación inédita de archivo, se reconstruyen las discusiones que Sánchez Vázquez sostuvo como militante de la delegación del Partido Comunista de España en México, su ruptura con la política centralista de la organización, su giro estético-praxeológico en la concepción del marxismo, su presencia en los debates de intelectuales y artistas posteriores a la Revolución cubana y, finalmente, su influjo en la crítica de arte del Estado espańol, vinculada al comunismo antifranquista. De este 
modo, se amplía el foco sobre las repercusiones de su relectura de los Manuscritos económico-filosóficos de I844, que intentaban alejarse por igual de la ortodoxia del diamat y del estructuralismo althusseriano.

Palabras clave Adolfo Sánchez Vázquez; cultura comunista; guerra fría; marxismo; Revolución cubana; estética; praxis.

Abstract The article analyzes the intellectual activity of Hispanic-Mexican philosopher Adolfo Sánchez Vázquez in the transatlantic axis of communist culture during the Cold War. Using unpublished file documentation, it reconstructs discussions in which Sánchez Vázquez participated as a militant of the Spanish Communist Party delegation in Mexico, his break from the organization's centralist politics, the aesthetic-praxeological turn in his conception of Marxism, his presence in intellectual and artistic debates after the Cuban revolution and, finally, his influence on art criticism in Spain, linked to anti-Franco communism. It thus expands on the scope of the consequences of his re-reading of the Economic and Philosophic Manuscripts of I 844 and his attempt to rethink Marxism beyond diamat orthodoxy and Althusser's structuralism.

Keywords Adolfo Sánchez Vázquez; communist culture; cold war; Marxism; Cuban revolution; aesthetics; praxis. 


\author{
JAIME VINDEL \\ UNIVERSIDAD COMPLUTENSE DE MADRID \\ DEPARTAMENTO DE HISTORIA DEL ARTE \\ ESPAÑA
}

\title{
México-La Habana-Madrid Adolfo Sánchez Vázquez en el eje transatlántico de la guerra fría
}

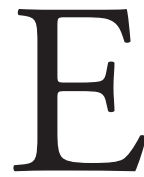

n su clásico Considerations on Western Marxism (1976), ${ }^{\mathrm{I}}$ Perry Anderson trazaba una genealogía de la evolución del marxismo occidental que se remontaba a las fuentes mismas del materialismo histórico. Para Anderson, el énfasis sobre la teoría económica del último Marx había construido una poderosa herramienta de lucha para la clase obrera que, sin embargo, poco o nada tenía que aportar en el plano de la estrategia política destinada a desbancar las estructuras del Estado burgués. Tal carencia explicaba la urgencia del marxismo revolucionario de las primeras décadas del siglo $\mathrm{xX}$ por paliar esa laguna teórica. El triunfo o la derrota de las insurrecciones comunistas en diferentes Estados-nación, sumados a la desviación oriental que representaba la Revolución soviética respecto al decurso previsto por la comprensión eurocéntrica del despliegue de los procesos históricos, explicaría la nueva etapa que se abrió a partir de los ańos veinte para el marxismo occidental. En este campo, la obra de Antonio Gramsci se configuró como una suerte de umbral entre dos épocas que aglutinaba, por una parte, al intelectual revolucionario, fundador y dirigente del Partido Comunista Italiano (PCI) y, por otra, al intelectual de la cultura, que ampliaba los problemas teóricos del marxismo hacia horizontes hasta entonces bastante inexplorados. El acento sobre

I. Perry Anderson, Considerations on Western Marxism (Londres: New Left Books, 1976). 
los aspectos culturales de la realidad social se complementaría en la vida posterior del marxismo occidental con los estudios relativos a ámbitos como la epistemología o la estética. Sin desmerecer los hallazgos de esa línea de pensamiento, que encontraría en la Escuela de Frankfurt uno de sus entornos más productivos, Anderson subrayaba la necesidad de engarzar sus aportaciones con lo que representaba una falla en la historia del marxismo occidental que siguió a la muerte de Gramsci: la ausencia de articulación entre la crítica cultural y la recomposición de una teoría revolucionaria adaptada — como había sugerido el pensador corso- a la singularidad y el grado de consolidación de las sociedades civiles en los Estados occidentales. ${ }^{2}$

\section{México-La Habana}

Pese a lo penetrante de sus reflexiones, Anderson no consideraba dos aspectos que nos ayudan a aproximarnos al valor de los escritos que el filósofo hispanomexicano Adolfo Sánchez Vázquez difundió a lo largo de los años sesenta. En primer lugar, es necesario recordar que, si bien es cierto que una de las repercusiones más duraderas de la estalinización de la III Internacional fue el alejamiento de los intelectuales de los órganos de dirección de los partidos comunistas, la retirada reflexiva hacia áreas como la estética no siempre implicó una renuncia a la incidencia en los debates políticos de esas organizaciones. Sánchez Vázquez — cuya sensibilidad literaria se remontaba a sus escritos poéticos de los años treinta en Málaga "la Roja"-, alumbró sus reflexiones críticas sobre estética justo después de abandonar sus cargos como representante de la delegación del Partido Comunista de España en México, en un momento en que ese ámbito se convirtió en el espacio interno y público para la formulación de aquellos disensos que la dirección no consentía en lo relativo a los aspectos estratégicos y organizativos del partido. ${ }^{3} \mathrm{Si}$, como ha subrayado José María Durán Medraño,

2. Anderson, Considerations on Western Marxism.

3. Con todo, es cierto que Sánchez Vázquez había mostrado anteriormente reticencias a asumir funciones que lo alejaran de sus tareas intelectuales. Así, en un informe firmado por "Gutiérrez" y en el que se registraban los debates sobre los materiales del V Congreso de la organización comunista, se consignaba la renuncia del filósofo tanto a ser el secretario del Comité Central de la delegación mexicana como a integrar este órgano. Los motivos de su negativa eran que "por un lado le inutilizaría para su trabajo intelectual, y además que él no se consideraba capaz de ser el secretario, por falta de experiencia de dirección, por su carácter irascible y por trabajar donde 
fue la estética la que facilitó a Sánchez Vázquez arribar a "una concepción plural del marxismo", 4 ese apunte adquiere un nuevo cariz desde la reconstrucción de la coyuntura política y el itinerario biográfico que planteo en este artículo. Por otra parte, se ha de tener en cuenta que, en el caso que me ocupa, al efecto provocado por el estalinismo al desplazar la reflexión intelectual de los órganos de dirección de los partidos comunistas se sumaba una tradición nacional de desconexión entre la vida intelectual y la actividad política, que no dejó de tener repercusiones en la historia del movimiento obrero español durante todo el siglo. Las constantes sospechas sobre el papel de los intelectuales al interior de la delegación mexicana del partido las contestó Sánchez Vázquez en I954, en un intento de suturar esa escisión histórica:

No hay problema de intelectuales en el P[artido] si esto se entiende como problemas de un grupo o cantón aparte dentro del P[artido]. Hay los problemas de la política cultural del $\mathrm{P}$ [artido], dentro de la cual les cabe, como es natural una mayor responsabilidad y participación a los intelectuales del $\mathrm{P}$ [artido]. Pero, los problemas de la política cultural del $\mathrm{P}$ [artido] son de todo el $\mathrm{P}$ [artido]. Los objetivos de esta política están subordinados a la política general del $\mathrm{P}$ [artido] y no son objetivos específicos de los intelectuales. El trabajo de los intelectuales hay que verlo a la luz de esta concepción. Cuando un intelectual del $\mathrm{P}$ [artido] reclama el derecho a que no se frene torpemente su labor de creación, no lo hace [o no] debe hacerlo porque se le frena el placer personal de la creación, de su obra propia, sino porque considera o debe considerar que se está frustrando una aportación suya al P[artido].5

trabaja”. Sin embargo, en última instancia se plegaba a lo que determinara el Partido e insistía en no rehuir sus responsabilidades. Archivo Histórico del Partido Comunista de España (en adelante AHPCE), Emigración política, caja I02/6.4 (México-correspondencia), II de junio de 1955, f. 2.

4. José María Durán Medraño, "Arte y humanismo en el pensamiento de Adolfo Sánchez Vázquez. ¿Es posible una teoría del arte a partir de los escritos de Karl Marx?”, De Raiz Diversa 2, núm. 4 (julio-diciembre, 20I5): I9I.

5. AHPCE, Emigración política, caja IO2/6.I (Reuniones), "Pleno organización de Méjico. Discusión tema Felipe Muñoz Arconada”, mayo de 1954, f. I. En esa intervención Sánchez Vázquez aún sostenía posturas sumamente ortodoxas respecto a las prácticas artísticas de vanguardia, lo que le llevaba a realizar una valoración políticamente sesgada del sentido del arte abstracto español: "La consagración oficial del arte abstracto, es decir, del arte más desprovisto de vida, de contenido, y en general, toda la orientación de la cultura oficial muestran claramente que en nuestro país, bajo la servidumbre ideológica del imperialismo, la cultura oficial está en una vía muerta”, en AHPCE, Emigración politica, "Pleno organización", f. 2. 
En esa misma ocasión Sánchez Vázquez admitía la desviación de los principios del partido que había padecido la delegación mexicana y relacionaba este hecho con la ausencia de un proyecto claro de actuación. ${ }^{6}$ La desconexión que la actividad de la organización padecía respecto a las discusiones intelectuales y a la clase obrera mexicanas era un síntoma del ostracismo en que había caído su dinámica interna. Para el filósofo, la Unión de Intelectuales Españoles, que en principio había tratado de solventar esa carencia, se inclinó después hacia la anemia y el dogmatismo que sucedieron a los impulsos de colaboración entre el comunismo antifranquista y la cultura republicana del Ateneo Español en México. ${ }^{7}$ Mientras tanto, la orientación de proyectos editoriales como las revistas Ultramar y Nuestro Tiempo había sido supeditada a las imposiciones de la anterior dirección del partido (en concreto, Sánchez Vázquez señalaba a los defenestrados Felipe Arconada y Esteban Vega), reacia a escuchar la opinión de los intelectuales. ${ }^{8}$ Como solución a esta crisis, el filósofo hispano-mexicano proponía una serie de medidas concretas, que incluían la recomposición orgánica, autónoma y democrática de los intelectuales del partido; la redefinición extensiva y no elitista del concepto de intelectual comunista (que debía abarcar "desde los intelectuales propiamente creadores — artistas y escritoreshasta las profesiones intelectuales de toda índole — maestros, médicos, abogados, etc.—"9 y que no debía restringirse a aquellos que poseyeran un título universitario); la reactivación no sectaria de la Unión de Intelectuales Espańoles; la conversión del suplemento cultural de España Popular en una revista de mayor alcance; la prolongación de la suspensión de la publicación Nuestro Tiempo (afectada de "prácticas viciosas") y su sustitución por una "revista mejor presentada y, al mismo tiempo, más ágil, más amena” Io en la que se articularan los debates culturales, las propuestas creativas de diversa índole y las informaciones relativas a la vida social bajo el franquismo; el fortalecimiento de la

6. Entre los males que afectaban a la organización, Sánchez Vázquez destacaba "la implantación de métodos caciquiles, la ausencia de dirección colectiva, el trato inhumano a los camaradas [y] la falta de crítica y autocrítica", en AHPCE, Emigración politica, "Pleno organización", f. 3.

7. "Fue nuestro sectarismo en el trabajo lo que nos fue aislando de nuestros aliados hasta quedarnos con una organización fácil de manejar, pero raquítica. Nuestro sectarismo impidió que viéramos también la evolución que se producía en el interior del Ateneo afirmándonos en el punto de vista falso de que debíamos permanecer al margen, con lo cual nos aislamos de un sector importante de la emigración intelectual", en AHPCE, Emigración política, "Pleno organización", f. 3.

8. AHPCE, Emigración politica, "Pleno organización", f. 3.

9. AHPCE, Emigración política, "Pleno organización", f. 3.

IO. AHPCE, Emigración política, "Pleno organización", f. 3. 
formación y el estudio de los intelectuales del partido; el estímulo de la discusión pública sobre las aportaciones en los campos de la historiografía, las artes plásticas y la literatura; la reconstitución de vínculos solidarios y diálogo crítico con los intelectuales del interior, que diluyera el mito por el cual la centralidad de la cultura antifascista se habría desplazado a México con la emigración posterior a la guerra civil; la conciliación entre la praxis creadora y la actividad cotidiana del partido; la recomposición de las relaciones con el Ateneo; la asunción de un papel destacado por parte de los intelectuales en el frente ideológico del partido, que en ese momento implicaba como tareas fundamentales su inserción en el movimiento por la paz (lo cual requería tender puentes con sectores intelectuales alejados de las convicciones ideológicas de la organización) y la crítica del pacto entre Estados Unidos y el régimen franquista. ${ }^{\text {II }}$

El problema quedó lejos de resolverse. Una muestra de ello es el documento titulado "Proyecto de plan para el trabajo de los intelectuales", que un año y medio después, en diciembre de 1955 , se redactó con motivo de una reunión de miembros del Comité Central de la organización mexicana. Tras extraer sendas citas de Dolores Ibárruri y Santiago Carrillo sobre las funciones de los intelectuales del partido, el documento planteaba las siguientes preguntas: "I. ¿Cómo, de qué forma, el Partido en México puede y debe ayudar a los intelectuales?; 2. ¿Cómo y de qué forma nuestros intelectuales pueden y deben contribuir a los esfuerzos del Partido, a ayudar al Partido?" I2 Con el objeto de responder a la primera de las cuestiones se proponía, en la antesala del proceso de desestalinización que seguiría al XX Congreso del PCUs (1956), superar el sectarismo del que hasta entonces había adolecido la organización. Sin embargo, no se renunciaba a ejercer una "vigilancia revolucionaria" sobre la actividad política y creativa de los intelectuales. Como medida de gracia adicional, se proponía incorporar a alguno de ellos a los órganos de dirección de la delegación, una decisión que explica la implicación de Sánchez Vázquez en las tensiones suscitadas con el Buró Político en los años posteriores. ${ }^{13}$

II. AHPCE, Emigración politica, "Pleno organización", ff. 4-5.

I2. AHPCE, Emigración politica, caja IO2/6.I (Reuniones), "Reunión miembros del cC de México, Intelectuales. Proyecto de plan para el trabajo de los intelectuales", diciembre de I955, f. 2.

I3. En el mismo documento el filósofo era requerido, junto a Wenceslao Roces, Juan Rejano y Gabriel García Narezo, para socializar las conclusiones del V Congreso del Partido entre los intelectuales de la emigración republicana. Sánchez Vázquez había asistido al congreso, celebrado en 1954 de manera clandestina cerca de Praga, como delegado de la organización en México. A él se le asignaba la misión de redactar un plan para la divulgación, en una compilación de artículos, 
Wenceslao Roces, Juan Rejano, Sánchez Vázquez y Josep Renau acometieron entonces la tarea de elaborar un plan de estudios para la formación tanto de los intelectuales del partido como del conjunto de los integrantes de la organización. ${ }^{14} \mathrm{La}$ acción intelectual de todos ellos debía favorecer tanto la "elevación teórica" de la militancia, insistiendo en la articulación entre la comprensión de los fundamentos del marxismo y la praxis política, como la divulgación cultural de ese trabajo en instituciones extrapartidistas como universidades, ateneos u otras asociaciones. En la línea de lo planteado un año antes por Sánchez Vázquez se apostaba por la creación de una nueva revista, que redefiniera el espacio de referencia ocupado hasta entonces por Nuestro Tiempo. Esa inquietud, que motivaría más tarde la aparición de Realidad, debía otorgar "orientación y claridad" sobre los problemas específicos de la cultura española, que abarcaba desde la emigración a México hasta los lectores radicados en Francia y España. En su lucha antifascista, anticlerical y antiimperialista, ese nuevo órgano de expresión había de proyectar su influencia sobre el conjunto de los países de América Latina, inspirándose en el impulso de publicaciones como la mexicana Cuadernos Americanos. Roces se sugería como el director adecuado de la revista, mientras que a Sánchez Vázquez se le asignaba provisionalmente el cargo de redactor en jefe. ${ }^{I 5}$ Éste se proponía, además, para integrar, junto a Renau y Gabriel García Narezo, la comisión de intelectuales de la delegación mexicana del partido, que a su vez debía nombrar comisiones de trabajo destinadas a cumplir funciones específicas, como el restablecimiento de las relaciones

de los aspectos más sobresalientes en las diferentes aportaciones al congreso. El filósofo tuvo que excusarse de ese encargo debido a la necesidad de centrarse en la redacción de su tesis de maestría "Conciencia y realidad en la obra de arte”. En todo caso, Sánchez Vázquez siguió figurando en la lista de camaradas a los que la organización encomendaba la redacción de los diversos artículos y, junto a Rejano, se le invitaba a dar una serie de conferencias — cuyos contenidos se sugería que fueran previamente concertados y aprobados por el Partido - en las que diera cuenta, "ante el Partido y ante las masas", de "su opinión sobre lo que ha visto en su viaje a través de las Repúblicas populares y la Unión Soviética; sobre la vida y las grandes realizaciones en los países que viven en el socialismo o marchan a ritmo acelerado hacia él", en AHPCE, Emigración politica, "Pleno organización", ff. 5 y 6.

I4. AHPCE, Emigración politica, "Pleno organización", f. 6.

15. AHPCE, Emigración política, "Pleno organización", ff. 7 y 8 . A renglón seguido, el documento abogaba por otorgar un giro radical a España Popular, superando el sectarismo de los contenidos y la rigidez del diseño, que habían comprometido el papel que debía jugar como semanario agit-prop entre la emigración española en México. Para esa nueva etapa, se proponía que Rejano asumiera el cargo de redactor en jefe. AHPCE, Emigración politica, "Pleno organización", f. 9. 
con la Agrupación de Periodistas o el Ateneo — de esta última responsabilidad se hacía también cargo Sánchez Vázquez. ${ }^{16}$ La creación de la revista teórico-cultural se haría más urgente en 1956, cuando, al hilo de las movilizaciones estudiantiles contra la dictadura, la dirección del partido consideró que era imprescindible acentuar su presencia en ese ámbito. ${ }^{17}$ Renau destacaba el acuerdo para que la estructura de la publicación incluyera tres secciones, dedicadas cada una de ellas a contenidos filosófico-políticos, literarios y de crítica de la economía política. Además del equipo administrador, se deseaba involucrar a un cuerpo de colaboradores más o menos estable que diera consistencia ideológica a la revista. El plan encargado a Roces, Sánchez Vázquez, Rejano y Renau debía hacerse cargo de la reprimenda que Santiago Álvarez, representante del Buró Político del PCE en México, había lanzado tras conocer una versión anterior. El 8 de septiembre de 1955, durante una reunión del Comité Central de la organización mexicana, Álvarez señalaba que en el anteproyecto del plan "el enfoque dado al trabajo de los intelectuales del P[artido] en México es una seria desviación de los principios del P[artido]" al introducir "el concepto de un superpartido a cargo de los cc. [camaradas] de profesión intelectual, lo que anula los principios básicos del P [artido], en el que cada órgano tiene su misión propia, claramente establecida en los Estatutos". ${ }^{18}$ Las funciones asignadas a la comisión de intelectuales eran cuestionadas en la medida en que entraban en

16. AHPCE, Emigración política, "Pleno organización", f. I5.

17. En su papel de comisario político, Santiago Álvarez responsabilizaría a la delegación mexicana por el retraso en la aparición de la revista, objetivo que resultaba "imperioso" en ese momento, "después de la lucha de los estudiantes madrileńos y del crecimiento de la oposición antifranquista en los medios intelectuales españoles en el interior del país". La coyuntura era además propicia por "la suspensión de las revistas de la oposición liberal", en AHPCE, Emigración política, caja I02/6.I (Reuniones), "Acta de la reunión de los miembros del C[omité] C[entral] W[enceslao] R[oces] y S[antiago] Á[lvarez]”, I5 de marzo de 1956, f. I. En esa reunión, Sánchez Vázquez propuso la constitución de un órgano colegiado para la dirección de la revista, en el que sugería incluir a Roces, Rejano y Narezo — este último como secretario de redacción. Los títulos posibles que se manejaron para la publicación fueron "España", "Nueva España", "Realidad" (que finalmente se elegiría), "Ebro", "Nuestra Patria", "Madrid”, "La Nueva España", "Revista Española”, "Cuadernos Españoles”, "Letras de España”, "El Español” y "Los Españoles”, en AHPCE, Emigración política, "Acta de la reunión”, f. 2. Lo primero que llama la atención, sin duda, es la españolidad de las propuestas, un aspecto que redunda en la misión que se encomendó a sí misma la cultura comunista del exilio como tesorera de las esencias nacionales, frente al extranjerismo del régimen franquista, aliado en primera instancia con el "nazi-fascismo" y posteriormente con el "imperialismo yanqui".

I8. AHPCE, Emigración politica, caja I02/6.I (Reuniones), "Acta y conclusiones de la reunión 
colisión con la acumulación de poder por los órganos de dirección, que en un gesto típico de la cultura política estalinista prefería recluir a aquéllos en una esfera de actuación limitada. En un pasaje del acta de la reunión, se acusaba de modo directo a Roces, Rejano y Sánchez Vázquez de haberse "desorbitado" en la aplicación de las conclusiones a las que llegaron tras reunirse para discutir sobre este tema con Fernando Claudín, quien en ese momento mantenía aún una posición alineada con la dirección del partido. ${ }^{19}$

Estas tensiones serían la antesala de una colisión mucho más agreste. Las fuerzas telúricas del movimiento comunista internacional se perturbaron en I956 por las revelaciones del XX Congreso sobre los crímenes de Stalin y la posterior insurrección húngara (que el PCE, tras justificar la intervención soviética, se encargaría de asociar — en una pirueta discursiva colosal — con las consecuencias de la deformación de los principios básicos del marxismo-leninismo y con la adopción por facciones del partido comunista húngaro del sectarismo denunciado en el congreso del PCUs). ${ }^{20}$ La agitación de los debates en el seno de la delegación del PCE en México se orientó hacia el reclamo de una mayor democracia y autonomía que superara el centralismo y el personalismo que regían las relaciones con el Buró Político. ${ }^{21} \mathrm{El}$ momento de mayor confrontación se alcanzó en septiembre de 1956, cuando tanto Roces como Sán-

mantenida por los miembros del C[omité] C[entral] en torno a los planteamientos hechos por el B[uró] P[olítico] sobre el trabajo de los intelectuales”, 8 de diciembre de 1955, f. I.

19. En su réplica a Álvarez, Rejano admitía la validez de las críticas de desviacionismo y se ceñía a las conclusiones del V Congreso, pero negaba la pretensión de crear una estructura superpartidista que desmereciera la jerarquía del Comité Central mexicano y señalaba que, en realidad, había sido Claudín quien les propuso medidas como la especialización de algunos camaradas en el estudio. AHPCE, Emigración política, "Acta y conclusiones", ff. 2 y 4.

20. En un documento elaborado por miembros del PCE y del PSUC (Partido Socialista Unificado de Cataluña, federado al PCE) en México, fechado en noviembre de 1956, se afirmaba que una de las enseńanzas de la experiencia húngara era "a dónde puede derivar la tendencia oportunista, nacionalista, chovinista, liquidadora, el desconocimiento de ciertos principios del Partido, el democratismo a ultranza, la lucha fraccional", en AHPCE, Emigración política (México), material microfilmado (Jacq 82), sin título, noviembre de 1956, f. 5. La invasión soviética se llegaba a justificar incluso en los términos de la resistencia al avance del fascismo y se contraponía a la doctrina de la "no intervención" que había prevalecido durante la guerra civil española, lo que da una idea de hasta qué punto la organización había quedado atrapada por el trauma y el imaginario políticos de los años treinta.

2I. Federico Álvarez estimaba que de los 350 militantes de la organización en México, aproximadamente 40 se manifestaban en contra de las pautas organizativas del Buró Político (entrevista con Federico Álvarez, México, D. F., 2I de octubre de 20I5). 
chez Vázquez discreparon del informe que Santiago Carrillo hizo circular tras el XX Congreso, especialmente en cuanto a sus consideraciones sobre la delegación mexicana. Sánchez Vázquez comunicó a Santiago Álvarez que, de guiarse por su impulso personal, renunciaría a la militancia. Los mexicanos insistieron en la necesidad de acabar con los "falsos métodos" que aislaban a la dirección de la base y exigieron una autocrítica por parte del Buró Político que nunca se produciría. Álvarez informaría que para Sánchez Vázquez "falta[ba] en la Resolución el espíritu del XX Congreso", de manera que, en lugar de contribuir a resolver el problema, tendía a agravarlo y acentuaba "discrepancias muy radicales entre el Comité y la Dirección". ${ }^{22}$ La dirección del partido respondió por medio de Álvarez y reprochó a los intelectuales del partido sus tendencias revisionistas, ligadas al oportunismo que la crisis del 56 había propiciado.

Tras haber solicitado, junto a otros camaradas, la sustitución de Álvarez como representante en México del Buró Político (lo que implicó que tuviera que viajar a París para reunirse con los miembros de ese órgano), Sánchez Vázquez se inclinó ante las órdenes del Partido, que impuso la destitución de todo el comité mexicano. ${ }^{23}$ Así lo demuestra su intervención del 8 de mayo de 1957 en una Asamblea de Información de la delegación mexicana. ${ }^{24}$ Allí, el filósofo reconocía los peligros que entrañaba la adopción de "métodos extraños" que introdujeran en el partido vicios de corte liberal o socialdemócrata. El autoritarismo y la rigidez de la cúpula de la organización (el "virreinato" compuesto en ese momento por Carrillo y Claudín) signaría la relación ambivalente con la orga-

22. AHPCE, Emigración politica (Cuba), material microfilmado (Jacq 8I), "Reunión con 'W[enceslao] R[oces], S[antiago] Á[lvarez] y J[uan] R[ejano]”, septiembre de 1956, ff. 2 y 3.

23. Sánchez Vázquez recordaba en retrospectiva ese encuentro sin tapujos ni acritud: "En I957, el BP [Buró Político] consideró que el conflicto no podía prolongarse más y, por este motivo, tuvimos varias reuniones con la máxima dirección del PCE en París. En estas reuniones la voz cantante por ambas partes la llevábamos Fernando Claudín y yo. El conflicto se resolvió de acuerdo con la aplicación habitual de las reglas del centralismo democrático: sometimiento incondicional de la organización inferior al centro. En este conflicto estaban ya, in nuce, todos los problemas - dogmatismo, autoritarismo, centralismo, exclusión de la democracia interna, entre otros- que reclamaban una solución nueva en el movimiento comunista mundial. La vieja solución dada a nuestro conflicto afectó seriamente mi actividad práctica, militante; desde entonces prometí ser sólo un militante de filas y consagrarme sobre todo a mi trabajo en el campo teórico”, en Adolfo Sánchez Vázquez, Del exilio en México. Recuerdos y reflexiones (México: Grijalbo, 1997), 60-6I. Véase también Gregorio Morán, Miseria y grandeza del Partido Comunista de España, I939-1985 (Barcelona: Planeta, 1986), 302-304.

24. AHPCE, Emigración politica, caja IO2/6.I (Reuniones), "Intervención de Adolfo Sánchez Vázquez en la Asamblea de Información del 8 de mayo de I957", 8 de mayo de I957, ff. 4 y 5. 
nización de Sánchez Vázquez, quien por otra parte tampoco escapó siempre al influjo del dogmatismo. ${ }^{25} \mathrm{La}$ crisis facilitó que el filósofo intensificara su compromiso con las tareas pendientes del trabajo intelectual. ${ }^{26} \mathrm{El}$ intelectualismo del exilio, despreciado por su desvinculación de la clase obrera mexicana y la política antiimperialista en América Latina (en contraposición a la titánica lucha de los militantes comunistas del interior), había fundamentado la acusación pequeñoburguesa que Carrillo lanzó contra los camaradas de la delegación mexicana en el encuentro parisino. A partir de entonces el trabajo de Sánchez Vázquez no se refugiaría en un mero repliegue sobre el espacio académico que habría justificado la invectiva, sino que trataría de entretejer esa labor con horizontes políticos no suspendidos del alambre táctico de la convivencia pacífica entre bloques en el plano internacional y de la política de reconciliación en el plano nacional. Ambas tesis apostaban por la contención tanto de procesos revolucionarios que pudieran afectar los equilibrios geopolíticos globales como de la eventual politización del antifranquismo en una línea que pudiera reavivar los rescoldos y el enfrentamiento de la guerra civil. La Revolución cubana sería el respiradero que ayudaría a Sánchez Vázquez a librarse del embotado aparato ideológico del PCE.

Tras el atisbo de rebelión, el efecto "pacificador" que generó la intervención del buró se destacó en las actas de las reuniones que se produjeron inmediatamente después. En ellas se insistía en que el comité de la organización mexicana "hacía suyas" las apreciaciones de la dirección, y se aseguraba de ese modo la unidad del partido. ${ }^{27}$ Sin embargo, se dejaba también constancia de las dis-

25. Por poner un ejemplo próximo en el tiempo, la Célula Carlos Marx de la Comisión Central de Control del Рсм (Partido Comunista Mexicano) envió con fecha io de febrero de 1958 una carta a Roces y Sánchez Vázquez cuestionando su reacción al artículo que Joaquín S. Macgrégor publicara en la revista Cuadernos Americanos, "Arte y pensamiento en el marxismo", vol. 95, núm. 5 (1957): 29-53. El contenido de la misiva era el siguiente: "Camaradas: Por varios medios nos han llegado informes acerca de la opinión que les merece nuestro camarada Joaquín S. Macgrégor a causa [...] de un artículo que sobre problemas de estética publicara en la revista 'Cuadernos Americanos'. Como de ninguna manera estamos de acuerdo con el calificativo de 'traidor a la ideología marxista' con que Ustedes lo han señalado, como un hecho comprobado, dado que lo divulgan, nosotros desearíamos conocer a fondo las argumentaciones que los llevaron a tal conclusión, a fin de valorar su justeza. Deseosos de conversar con Ustedes, les suplicamos se sirvan precisar la fecha que consideren oportuna para conocer sus puntos de vista sobre el asunto antes dicho, el cual merece una seria reconsideración”. Entre las firmas que acompañaban al texto aparecía la de José Revueltas. Archivo del Centro de Estudios del Movimiento Obrero y Socialista (en adelante CEMOS), PCM, caja 32, clave 29, exp. OI.

26. Sánchez Vázquez, Del exilio en México, 219.

27. AHPCE, Emigración política, caja IO2/6.I (Reuniones), "Conclusiones de la reunión de la 
crepancias que seguía generando la reconciliación nacional entre un número reducido de sus miembros, que sólo aceptaban esa doctrina por deberse a la disciplina militante y evitar el "democratismo" liberal. ${ }^{28}$ Esta disidencia interna conducía a constatar la necesidad de atajar la influencia de algunos miembros del partido para evitar el riesgo de disgregación. ${ }^{29}$ Entre ellos figuraba Federico Âlvarez, quien tras instalarse en Cuba en 1965 trabaría amistad con Roberto Fernández Retamar y ejercería de enlace en la isla durante las visitas que Sánchez Vázquez realizó a lo largo de los años sesenta. ${ }^{30}$ Aunque el filósofo hispano-mexicano se plegó a las directrices del Buró Político — hasta el punto de que se mostrara en él una "confianza ilimitada" durante las discusiones que se generaron a raíz de la trifulca interna- ${ }^{3 \mathrm{I}}$ la reprimenda coincidió con su distanciamiento de la dinámica cotidiana de la organización y la transfiguración estética de su disenso.

delegación del C.[omité] C. [entral] para examinar la situación de la organización del P.[artido] en México", I6 y 17 de junio de I957, f. I.

28. La apuesta de la dirección del PCE por la política de reconciliación nacional coincidió en el tiempo con la inserción progresiva del régimen franquista en el concierto internacional, que culminaría en I955 con el ingreso a la ONU. Las reticencias entre la cultura comunista del exilio a la hora de asumir esa doctrina deben entenderse con base en las contradicciones que implicaba para sus integrantes aceptar un punto de vista que contrastaba de manera radical con el que ellos mismos habían impulsado durante los años cuarenta, época en la cual se habían esmerado en construir la memoria del conflicto guerracivilista como una confrontación irreconciliable entre clases sociales y entre el comunismo y el fascismo.

29. "en el seno del Comité de México se perfila cada día más la existencia de una especie de conformismo respecto a ciertas falsas posiciones; una cierta tendencia a dejarse arrastrar por la línea de los menores conflictos posibles; de no hacer frente con la necesaria energía y sobre una base de principios, a la actitud de los que la carta califica como calumniadores y revisionistas; de pasar fácilmente por alto posiciones de ciertos camaradas respecto a la interpretación de los principios del P.[artido], de la línea política, del papel de la dirección y referente a los problemas de México. Por ello, existe el peligro de que si no se toman medidas puedan jugar un papel demasiado destacado en la organización y sean elegidos para la conferencia, militantes cuya actitud y conducta no corresponde a las necesidades y las exigencias del P.[artido]", en AHPCE, Emigración política, "Conclusiones de la reunión”, f. 2.

30. Federico Álvarez había solicitado ir antes a Cuba, con la intención de olvidar su experiencia política en México. Permaneció en el país caribeño hasta 197I, donde se desempeñó como profesor en la Universidad de La Habana (entrevista con Federico Álvarez, México, D. F., 2I de octubre de 20I5).

3I. Así se reflejaba en las actas de las reuniones de Santiago Álvarez con el comité mexicano. AHPCE, Emigración política, caja IO2/6.I (Reuniones), título, 20 de junio de 1957, ff. I y 2. 
La tensión estética de los debates políticos al interior del PCE alcanzaría su cenit en 1963. Durante el Congreso de Arras, celebrado poco después de la ejecución de Julián Grimau, ${ }^{32}$ Santiago Carrillo mostró primero su malestar y salió después despavorido de la sala de reuniones cuando Francesc Vicens se atrevió a cuestionar las tesis de Plejanov. ${ }^{33}$ La frustración del secretario general se acentuó más al haber concebido el encuentro como un acontecimiento destinado a homogeneizar las opiniones de los intelectuales del partido. Poco después, Claudín (hasta entonces segundo de abordo) aprovechó la tribuna de la revista Realidad, recién estrenada como espacio de debate cultural de la organización, para publicar un artículo titulado "La revolución pictórica de nuestro tiempo". En él, la crítica del realismo socialista propugnado por el diamat (bastante endeble desde el punto de vista teórico y desfasada en el plano histórico) se presentaba como una excusa para cuestionar en una escala más amplia el esquematismo teórico de la organización. ${ }^{34}$ Claudín defendía las aportaciones plásticas del modernismo frente al atraso estético que detectaba en el realismo socialista. Con el Guernica como trasfondo simbólico y político de referencia, mostraba especial predilección por el expresionismo, que en su opinión había sabido conjugar la experimentación plástica con el abordaje de "los grandes problemas sociales de nuestro tiempo: la guerra atómica y la lucha contra ella, los horrores del fascismo, la tortura, la lucha de los pueblos coloniales por su independencia, la lucha revolucionaria del proletariado y los campesinos, el trabajo, etc." ${ }^{35}$ Los fundamentos teóricos de esa nueva posición estética estarían reforzados por la publicación en el segundo número de la revista del artículo de Sánchez Vázquez "Ideas estéticas en los Manuscritos económico-filosóficos de Marx", que había aparecido previamente en la revista mexicana Diánoia ${ }^{36}$ y un año más tarde en la cubana Casa de las Américas (1962), donde el filósofo anticipaba el marco conceptual que después ampliaría en su libro Las ideas estéticas de Marx. ${ }^{37}$

32. Grimau, militante clandestino del PCE en España, fue condenado a muerte y ejecutado por la dictadura franquista el 20 de abril de 1963 , acusado de haber cometido crímenes en la retaguardia durante la guerra civil, tras ser torturado por el régimen.

33. Morán, Miseria y grandeza del Partido Comunista de España, 370.

34. Fernando Claudín, "La revolución pictórica de nuestro tiempo", Realidad. Revista bimestral de cultura y politica I, núm. I (1963): 2I-49.

35. Claudín, "La revolución pictórica de nuestro tiempo", 42 y 43.

36. Adolfo Sánchez Vázquez, "Ideas estéticas en los Manuscritos económico-filosóficos de Marx", Diánoia 7 , núm. 7 (I96I): 236-258.

37. Claudín y Sánchez Vázquez mantendrían una correspondencia entre 1968 y 1973, en la que discutieron sobre cuestiones relativas a la filosofía de la praxis y la crisis del movimiento 
Ante la afrenta de Realidad, Carrillo reaccionó con la expulsión de Claudín y Jorge Semprún (quien con el pseudónimo de "Federico Sánchez" también había participado en ese primer número) de los órganos de dirección de la revista y del Comité Central del partido. Para borrar la mancha, recurrió además a Renau para que replicara a los díscolos en dos números de la revista. ${ }^{38}$ La férrea cultura política estalinista de Renau ya había suscitado en 1954 un enfrentamiento del artista con Roces, Rejano y el propio Sánchez Vázquez. Roces, embarcado en la traducción al castellano de El capital, había sido reprendido por priorizar su integración en la universidad mexicana y relegado de sus cargos como miembro del Comité Central "por su participación constante en las violaciones de los principios y normas orgánicas". ${ }^{39}$ En las reuniones que se sucedieron después, Renau acusó de "confusionista" a Sánchez Vázquez, pues percibía, en su intento de democratizar las estructuras internas de la organización, una posición pequeñoburguesa reticente "a aceptar la primacía de las causas políticas sobre las orgánicas". ${ }^{\circ} \mathrm{La}$ acusación de Renau surtió efecto. Tras ella, Sánchez Vázquez decidió retirar sus objeciones y desbloquear la elección

comunista. Tiempo después, durante la entrega a Sánchez Vázquez del doctorado Honoris Causa por la Universidad de Cádiz (Is de mayo de 1987), Claudín establecería un paralelismo entre las trayectorias seguidas por él y Sánchez Vázquez luego de la crisis del movimiento comunista en I956, aprovechando para ajustar cuentas en el deber y el haber con el filósofo hispano-mexicano: "Adolfo Sánchez Vázquez y yo mismo figuramos entre los que recorrimos ese camino, a veces encontrándonos conflictivamente en la trayectoria, como cuando yo fui encargado por la dirección del PCE de censurar y sancionar las posiciones críticas de Sánchez Vázquez en México, o cuando ańos después él hubo de aceptar disciplinadamente, como miembro del partido, mi exclusión del mismo", en Fernando Claudín, "La generación del marxismo-leninismo", en En torno a la obra de Adolfo Sánchez Vázquez (filosofia, ética, estética y política), ed., Gabriel Vargas Lozano (México: Universidad Nacional Autónoma de México, 1995), 50, véase también Adolfo Sánchez Vázquez, Las ideas estéticas de Marx (México: Era, 1965).

38. Josep Renau, “Auditur et altera pars: sobre la problemática actual de la pintura” (I) y (II), Realidad, núm. 3 (1964): 70-II7 y núm. 5 (I965): I07-I35.

39. AHPCE, Emigración política, caja I02/6.3 (Resoluciones), "Resoluciones del pleno de delegados de la organización del PCE en México", f. 6, ca. 1954.

40. "Aparte de su intervención sobre la cuestión de los intelectuales comunistas, este camarada no ha intervenido sobre los problemas candentes aquí debatidos. Sólo ha dicho unas palabras, muy pocas, en dos ocasiones. Y no lo ha hecho para ańadir claridad comunista a nuestras deliberaciones, sino para confundir más aún los problemas fundamentales que tenemos planteados", en AHPCE, Emigración política, caja I02/6.I (Reuniones), "Reunión del Comité del PCE en México", Io de agosto de I954, f. 5. Poco después de estos enfrentamientos, la correspondencia con Santiago Álvarez de la dirección del partido revelaba su preocupación por "la realización de asambleas generales", y su apuesta "por el fortalecimiento de la organización de base", en AHPCE, Emigración política (Cuba), 
del nuevo comité mexicano, que fue aprobado por aclamación. Sin embargo, a la salida de la reunión se produjo una fricción entre el filósofo y el artista. Sánchez Vázquez acusó a Renau de calumniarle por haber recuperado un párrafo de la intervención de Stalin en el XIII Congreso del pCus en mayo de I924, en la que con objeto de criticar a la oposición trotskista atacó a Yevgueni Preobrazhenski por alabar la línea política del partido al tiempo que cuestionaba sus formas organizativas. ${ }^{41}$

La necesidad de que Carrillo recurriera a Renau ante la nueva sublevación de los intelectuales del partido se debió tornar más urgente al observar la buena acogida de los artículos de Claudín y Semprún en otros contextos. Así, José María González Jerez, quien desarrollaría una larga carrera trabajando como responsable de prensa, publicaciones, radio y televisión del partido en Cuba durante más de treinta años tras la revolución de 1959, recibió una misiva con fecha I8 de enero de 1964 sobre el primer número de Realidad. Escrita por el propio Santiago Álvarez, la carta daba cuenta de la visita a Cuba de Manuel Azcárate, uno de los intelectuales de referencia del partido, y alertaba sobre las discusiones que la dirección del partido estaba sosteniendo en torno al artículo de Semprún, que en un principio iba a ser divulgado en Cuba. Además de su supuesta "superficialidad", los problemas que se identificaban en el texto se vinculaban a "formulaciones y expresiones que no responden exactamente a nuestra posición de partido respecto a los problemas del culto a la personalidad". ${ }^{42}$ Por ese motivo se prohibía su publicación hasta nuevo aviso. Por otra parte, González Jerez, miembro del comité del partido en Cuba, avanzaba en una carta, escrita tan sólo dos días después (desconocedor del aviso de Álvarez), que el ensayo de Claudín había "causado sensación" e informaba que ya había sido difundido en formato mimeografiado por el director del Instituto Cubano de Artes e Industrias Cinematográficas (ICAIC), Alfredo Guevara. Para probable disgusto del Buró Político, González Jerez añadía que el artículo de Claudín (quien había visitado previamente Cuba) también iba a ser publicado por la revista Cuba Socialista en su número de febrero. Y para

material microfilmado (Jacq 65), "Carta al camarada Santiago Álvarez acerca del estudio sobre los materiales enviados desde México por Santiago Álvarez”, primera semana de enero de 1955, f. I.

4I. AHPCE, Emigración politica, "Carta al camarada", ff. 5-6.

42. AHPCE, Cuba, caja IO2/4.4. (Correspondencia), "Carta de Santiago Álvarez a José María González Jerez”, I8 de enero de I964, f. I, Álvarez insistiría en una carta posterior en censurar el trabajo fraccionalista que estaban realizando Semprún y Claudín tras ser expulsados del Comité Central del partido, 3 de octubre de 1964 , f. I. 
terminar de rematar la jugada pronunciaba un juicio positivo sobre su contenido:

considero que el trabajo de Claudín es una valiosa aportación a un tema tan polémico. Además estimo que la forma abierta, libre de moldes estrechos en que aborda los problemas del arte pictórico [...] es correcto. Es una gran contribución, bien razonada y documentada que, en Cuba, va a causar sensación... y me imagino que también en otros países. ${ }^{43}$

La incomodidad del partido con el papel que a partir de entonces tendrían Semprún y Claudín como voces disidentes se prolongaría durante la década de los sesenta. El primero de ellos formaría parte de la cohorte de intelectuales que acudieron al Congreso Cultural de La Habana en 1968, donde se encontraría con Sánchez Vázquez. En cuanto a Claudín, la difusión de su libro Las divergencias en el partido fue el motivo de una carta posterior dirigida a Santiago Álvarez y fechada en La Habana el 6 de junio de $1965 .{ }^{44}$ La publicación acusaba a la dirección del partido de haber recurrido a métodos estalinistas para acabar con la disidencia interna. Lo más interesante del relato remitía a la conversación que González Jerez, el autor de la misiva, había mantenido con el crítico de arte José María Moreno Galván, de visita en Cuba por esas fechas. Moreno Galván reconocía que los círculos intelectuales del partido habían mantenido una relación estrecha con Claudín y Semprún y afirmaba que "en la discusión de ese problema había ciertas dudas en cuanto al enfoque de la situación espańola", lo que merecía profundizar en las diferencias que habían distanciado a Carrillo y Claudín en torno a la lectura de la coyuntura neocapitalista que atravesaba la sociedad española.

Moreno Galván esbozaría sus impresiones cubanas en un artículo publicado en la revista Triunfo. ${ }^{45}$ En él subrayaba ante todo la sensación de libertad creativa que había percibido entre los artistas de la isla. Tras un periodo en el que se habría presentado el riesgo de caer en el sectarismo, se congratulaba de que los organismos culturales de la revolución hubieran apostado por una

43. AHPCE, Cuba, caja IO2/4.4. (Correspondencia), "Carta de José María González Jerez a Santiago Álvarez", 20 de enero de I964, f. 5.

44. AHPCE, Emigración politica (Cuba), material microfilmado (Jacq 327), "Carta a Santiago. De un libro de Claudín 'Las divergencias en el partido'. La visita de Moreno Galván y las conversaciones con él”, 6 de junio de 1965 , f. I.

45 "Artistas en la Cuba de hoy", Triunfo, núm. 162, io de julio de 1965, 9. 
apertura estimulante para los artistas, cuya "agudeza ideológica" no encontraba para el crítico parangón posible. Más abajo analizaré el modo en que esta conexión cubana puede rastrearse en el trabajo de otros críticos españoles próximos a la órbita del partido, como Valeriano Bozal. Uno de los aspectos más llamativos de la carta enviada a Santiago Álvarez es la sorpresa que había causado en su interlocutor la falta de complejos con la que Moreno Galván denunciaba al régimen franquista durante su paso por Cuba. ${ }^{46}$ Visto a la distancia, puede parecer extraño que las actividades de un crítico de arte inquietaran a un Estado autoritario como el franquista, pero tanto Moreno Galván como Bozal figuraban entre los intelectuales que fueron vigilados por la dictadura. ${ }^{47}$

\section{La Habana-Madrid}

El segundo aspecto no suficientemente destacado por Anderson es que la estética no siempre representó un repliegue teórico que desmereciera la actualización de la política revolucionaria como elemento vertebral del materialismo histórico. Al margen de las distancias cronológicas y los alcances teóricos, los escritos estéticos de Sánchez Vázquez intentaron diagramar, en este sentido, una operación equivalente a la que Gramsci realizara por medio de la cultura. El retorno que el filósofo hispano-mexicano propuso sobre la obra del primer Marx aspiraba a considerar la estética, más allá de los problemas sociológicos y formales específicos del arte, como un elemento integrado en una nueva filosofía de la praxis. Tras la crisis interna, Sánchez Vázquez relajaría su implicación en la actividad cotidiana de la delegación mexicana del PCE para centrarse en la produc-

46. "M.[oreno] G.[alván] me dio muy buena impresión. Creo que es un poco impulsivo en cuanto a no preocuparse demasiado de los riesgos [...] sus propias declaraciones en Cuba son bastante críticas respecto al régimen, tal vez, me parece a mí, excesivamente críticas para quien va a regresar en estos días", en AHPCE, Emigración política (Cuba), material microfilmado (Jacq 327), “Carta a Santiago. De un libro de Claudín 'Las divergencias en el partido'. La visita de Moreno Galván y las conversaciones con él”, 6 de junio de 1965 , f.3.

47. En el Archivo General de la Administración (en adelante AGA), Alcalá de Henares, Madrid, España, se conservan los expedientes de Bozal y Moreno Galván redactados por la Oficina de Enlace del Ministerio de Información y Turismo. Entre ellos se incluye un informe de la presentación del libro de Bozal, El realismo: entre desarrollo y subdesarrollo (I966), publicado por la editorial madrileña Ciencia Nueva, en la que dos años más tarde él mismo compilaría una serie de escritos sobre arte de Marx y Engels. Fechado el is de enero de 1967, el relato del acto subraya que Bozal se encontraba acompañado de Moreno Galván. AGA, caja 42/o8828. 
ción teórica de un marxismo renovado. La aproximación a los textos iniciales del fundador del materialismo histórico rescataba el componente antropológico de la estética entendida como teoría de la sensibilidad. El objetivo último era reconsiderar la dialéctica entre arte y trabajo como parte de una "praxis creadora” de alcance revolucionario. ${ }^{48}$ La estética, por tanto, no poseía para Sánchez Vázquez un carácter pasivo-contemplativo, sino que era el elemento activo que vertebraba la relación mutuamente constitutiva (dialéctica) entre la percepción de la realidad por los sentidos humanos y la transformación del mundo natural y social. ${ }^{49}$ En su trabajo inmediatamente posterior, la "praxis artística" se

48. Sánchez Vázquez, "La praxis creadora", Cuadernos Americanos I49, núm. 6 (I966): II4-I25. 49. Para Durán Medrańo, la dimensión activa de la estética (en su doble vertiente, antropológica e histórica) no fue, sin embargo, asumida siempre de modo coherente por Sánchez Vázquez, quien al retrotraerla ante todo a los sentidos de la vista y el oído, tendió a concederle un componente hegeliano: "Dentro del discurso hegeliano los sentidos estéticos — vista y oído- funcionan en el modo de la contemplación (Anschauung), que presupone una distancia necesaria con el objeto percibido [...] Mientras que la forma de percepción sensorial adecuada a la relación estética es la contemplación, Hegel excluye de ésta los sentidos prácticos, es decir, el olfato, el gusto y el tacto, porque en ellos la obra de arte deviene anulada [... No deja de resultar extraño que ASV asuma acríticamente el ojo y el oído como sentidos propiamente estéticos. Siendo conscientes de la crítica de Marx al modo de contemplación en la primera tesis de las Tesis sobre Feuerbach, no parece muy coherente asumir la crítica de Marx al materialismo feuerbachiano por haberse quedado preso de la contemplación olvidándose de la práctica real, y — sin embargo — mantener la contemplación para el modo de percepción estético”. Matizaré más abajo esta apreciación al glosar la crítica del propio Sánchez Vázquez a la estética como contemplación. Por otra parte, para Durán Medrańo el idealismo estético de Sánchez Vázquez se habría infiltrado en el núcleo mismo de su concepto de praxis, entendida como "una estructura o sustancia fundamental que caracteriza a todos los seres humanos por igual, independientemente de las condiciones históricas concretas”. Frente al rescate en clave estética o de teoría del arte de las reflexiones de Marx en torno a la relación entre arte y capitalismo, este autor aboga por afinar los instrumentos que el filósofo de Treveris diseñó para profundizar en una crítica de la economía política del arte ("Arte y humanismo en el pensamiento de Adolfo Sánchez Vázquez”, 200-205). Al margen de la valoración que haga de esa pretensión, sí que me gustaría apuntar que, en mi opinión, las posiciones teóricas de Sánchez Vázquez no supieron liberarse de la configuración estético-praxeológica de la modernidad como aquella relación sensible y política de exterioridad con el mundo natural y social determinada por los procesos de acumulación primitiva. En esa relación, la matriz emancipadora de la racionalidad y la sensibilidad modernas apenas alcanza a disimular su contracara instrumental: la división sexual, racial e internacional del trabajo, así como el dominio de la naturaleza. La estética aparece entonces como la distancia consistente en la sublimación perceptiva de lo real; la praxis, como acción voluntarista tendente a sobrepasar aquella escisión constitutiva sin poner en crisis los fundamentos históricos de su emergencia: la generalización a escala global de las categorías de la economía política (en particular, del valor-trabajo), con sus diversas formas de 
articularía con una investigación más ambiciosa y general sobre el concepto de praxis, cuyos resultados se compilarían en la tesis doctoral del filósofo, publicada posteriormente en formato de libro con el título Filosofía de la praxis. ${ }^{50}$

Lo significativo en este punto es que, si bien la primera matización que hacía a los planteamientos de Anderson se remite ante todo a la historia de las discusiones internas del PCE, esta segunda encontraba su espacio histórico de inscripción en un contexto geopolítico no alineado, al menos en una primera etapa, con las intrigas del movimiento comunista supeditado a los designios de Moscú. El horizonte abierto por la Revolución cubana de 1959, sumado a su ingreso en enero de ese ańo como profesor de tiempo completo de la UNAM, impulsaron y facilitaron la ruptura de Sánchez Vázquez con el diamat. La relación del filósofo con la revolución fue de mutua retroalimentación. ${ }^{5 \mathrm{I}} \mathrm{Si}$ bien, las ideas estéticas de Sánchez Vázquez nutrieron a los círculos culturales y artísticos cubanos de un referente alternativo a las rigideces del realismo socialista, éste se sirvió del nuevo marco abierto por la Revolución para ensayar una concepción de la filosofía de la praxis que atacaría tanto la visión mecanicista

alienación y explotación, en y más allá del sistema-mundo capitalista. Estética y praxis, más que como regímenes de experiencia mutuamente excluyentes, aparecen desde esta perspectiva como parte y contraparte de una misma estructura (moderna) de sentimiento en la configuración de las relaciones entre el ser social y el mundo.

50. Adolfo Sánchez Vázquez, Filosofía de la praxis (Ciudad de México: Grijalbo, 1967).

5I. Así lo seńalaba Roberto Fernández Retamar en su discurso con motivo de la entrega del doctorado Honoris Causa a Sánchez Vázquez por la Universidad de La Habana el i6 de septiembre de 2004: "si Sánchez Vázquez ha podido decir que la Revolución cubana influyó en su pensamiento, también es verdad que ese pensamiento prestó servicios que recordamos muy bien en defensa de una línea estética que manteníamos en momentos de intensa lucha ideológica”. El discurso, titulado "Sánchez Vázquez: del pulso ardiendo a la razón apasionada”, puede revisarse en: http://www.rebelion.org/noticia.php?id=6725, consultado el to de marzo de 2017. Retamar recordaba que, en todo caso, la simpatía del filósofo hispano-mexicano por el régimen cubano no estuvo exenta de crítica. En el Taller Cultura y Revolución, convocado por el Ministerio de Cultura y la Casa de las Américas en La Habana los días 4 y 5 de enero de 1999, Sánchez Vázquez leyó una contribución sobre el tema "Cultura y revolución: a cuarenta años de 1959" en la que subrayaba los logros, pero también los deméritos de la Revolución. A estos últimos contraponía la necesidad de avanzar hacia formas de propiedad social no estatal de los medios de producción y hacia una democracia real que permitiera la pluralidad política al interior del socialismo. Sánchez Vázquez identificaba en ese doble propósito la posibilidad de trascender definitivamente la impronta del marxismo-leninismo soviético sobre la historia del proceso cubano, véase Adolfo Sánchez Vázquez, "La Revolución cubana y el socialismo", Taller Cultura y Revolución: "Cultura y revolución: a cuarenta años de 1959", La Habana, 4 y 5 de enero, I999, en Adolfo Sánchez Vázquez, El valor del socialismo (Ciudad de México: Icaria, 2000), 156. 
de la historia afín al materialismo dialéctico estalinista como el estructuralismo althusseriano, que tendía a ver en aquélla un "proceso sin sujeto".

Mucho antes que el Mayo francés, el foquismo táctico del Che Guevara había roto en la práctica los supuestos teóricos de ambas interpretaciones. De modo atrevido, David Craven sugirió que el gesto teórico de Sánchez Vázquez operó en el campo estético un corte similar a la impugnación del marxismoleninismo (la idea del partido de vanguardia como metodología de conciencia, organización y acción) cristalizada en la Revolución cubana. ${ }^{52}$ La cercanía de Sánchez Vázquez con los planteamientos teórico-prácticos del Che puede rastrearse en diversos artículos publicados durante los años sesenta por el filósofo hispano-mexicano en la revista Casa de las Américas. Por su parte, la formación marxista del Che había bebido de las traducciones al español de El capital $^{53}$ y los Manuscritos económico-filosóficos, ${ }^{54}$ realizadas en los años cincuenta en México por Roces. Ambos compartían la concepción humanista de la praxis revolucionaria y la defensa de una estética no supeditada a la normatividad del realismo socialista. 55 Como ha señalado Néstor Kohan, uno de los efectos balsámicos del XX Congreso fue el retorno de las discusiones en torno a la cuestión de la alienación. En ese plano, los Manuscritos resultaron decisivos tanto para la superación del determinismo estructural de las "leyes de la dialéctica" en los escritos y la praxis política del Che como en la ruptura estética con el zhdanovismo emprendida por Sánchez Vázquez en el umbral entre la década de los cincuenta y los sesenta. La síntesis dialéctica de una "historia estructu-

52. David Craven, Art and Revolution in Latin America, I9I0-I9go (Yale: University Press, 2002).

53. Carlos Marx, El Capital (Ciudad de México: Fondo de Cultura Económica, 1959).

54. Carlos Marx, Manuscritos económico-filosóficos (Barcelona: Grijalbo, 1962).

55. Para el Che, el realismo socialista representaba un "dogmatismo exagerado" que gravaba el arte socialista del siglo xx latinoamericano con la herencia eurocéntrica decimonónica del arte burgués. Su defensa en ciertos sectores del partido y de la clase funcionarial se debía, en su opinión, a la falta de conocimientos y de audacia que llevaba a defender "la simplificación, lo que entiende todo el mundo". Esta dinámica anulaba la "auténtica investigación artística”, al reducir "el problema de la cultura general a una apropiación del presente socialista y del pasado muerto (por tanto, no peligroso)". Pese a tender a ver en el arte de vanguardia del siglo xx una manifestación decadente del hombre enajenado (aspecto en que se distanciaba de la interpretación arrojada por Sánchez Vázquez en Las ideas estéticas de Marx, publicado ese mismo año), los márgenes de libertad en el arte (pos)revolucionario debían abrir la experiencia del futuro frente a ese retorno de lo ya caducado. Ernesto Che Guevara, "El socialismo y el hombre en Cuba", Marcha, I2 de marzo de 1965 , reproducido en Ernesto Che Guevara, El socialismo y el hombre nuevo (Ciudad de México: Siglo XXI, 1979), I2-I3. 
ral", propuesta por este último para superar las antinomias entre el férreo dictamen del estructuralismo y las inclinaciones subjetivistas del "optimismo de la voluntad", ${ }^{56}$ coincidían con la posición sostenida por el Che, para quien "se puede y se debe forzar la marcha dentro de lo que objetivamente es posible, lo que no significa [...] sino que en la sociedad y la historia hay unidad diferenciada de sujeto-objeto". ${ }^{57}$

Tras la muerte del revolucionario argentino, Sánchez Vázquez publicó un artículo titulado "El socialismo y el Che", en el que daba cuenta del encuentro que, junto a otros intelectuales, habían mantenido a comienzos de $1964 .{ }^{58} \mathrm{Lo}$ más llamativo de esa nota es la insistencia del filósofo en deslindar al Che de la imagen del héroe romántico, y enfatizar su capacidad como revolucionario marxista para inscribir la voluntad de la acción en las contradicciones objetivas de la historia. Al inspirarse en el El socialismo y el hombre en Cuba, Sánchez Vázquez reiteraba la importancia del legado del Che a la hora de plantear un socialismo que articulara la crítica de la economía política con la recuperación del sujeto moral. El Che Guevara ejemplificaba el humanismo concreto, la síntesis entre utopía y realismo que alejaría esa sensibilidad filosófica de sus formulaciones más abstractas o idealistas, pero también de las concepciones mecanicistas del curso de la historia. 59 En el plano estético, la simpatía por el revolucionario argentino se vinculaba con la crítica del realismo (y de la teoría del reflejo) y con la extensión de las posibilidades plásticas del arte socialista. El concepto de "praxis creadora” representaba para Sánchez Vázquez una

56. Adolfo Sánchez Vázquez, "Estructuralismo e historia", Casa de las Américas, núm. 55 (I969): 3I-43.

57. Néstor Kohan, De Ingenieros al Che. Ensayos sobre el marxismo argentino y latinoamericano (Buenos Aires: Biblos, 2000), 207.

58. Se trató de la primera visita a la isla de Sánchez Vázquez, quien un año antes había publicado en la revista Casa de las Américas su artículo sobre las ideas estéticas del primer Marx. En 1964 Sánchez Vázquez pronunció además la conferencia "Estética y marxismo" en la Unión de Escritores y Artistas de Cuba (recogida más tarde por la revista Unión) e impartió una serie de charlas en la Universidad de La Habana. Tras la edición cubana de su libro Las ideas estéticas de Marx, Sánchez Vázquez retornó a La Habana con motivo del Congreso Cultural y del ciclo de conferencias "Problemas fundamentales de una estética marxista", que tuvo lugar en la Universidad de Oriente en 1968. Véase "El socialismo y el Che", Casa de las Américas, núm. 46 (I968): I49-I5I.

59. "La lección de la vida y la muerte del Che confirma [...] que la historia la hacen los propios hombres, y que la revolución solo pueden hacerla ellos si se elevan de la condición de mero efecto de una estructura social a sujetos conscientes de la historia" (Adolfo Sánchez Vázquez, "El socialismo y el Che”, Casa de las Américas, núm. 46, 1968, en Adolfo Sánchez Vázquez, El valor del socialismo [Ciudad de México: Icaria, 2000], 19). 
superación de los dilemas entre realismo y abstracción. Gerardo Mosquera apuntó la recepción positiva que la recuperación del primer Marx tuvo ya tempranamente en la obra de José Antonio Portuondo, esteta marxista cubano que se hacía eco de las reflexiones de Sánchez Vázquez en Estética y revolución, libro publicado en La Habana en $1963 .{ }^{60}$ El influjo de ese gesto teórico se prolongaría en América Latina hasta las conferencias que el filósofo pronunciaría a principios de los ochenta en la Escuela Nacional de Artes Plásticas de Managua, centradas en las relaciones entre el arte abstracto y la semiótica y cuyo impacto sobre los artistas alineados con la Revolución sandinista ha sido señalado por Craven. ${ }^{61}$

Sánchez Vázquez fue uno de los intelectuales presentes en el Congreso Cultural de La Habana. El congreso se celebró en el hotel Habana Libre entre el 4 y el in de enero de 1968. Las palabras que el presidente de la República, Osvaldo Dorticós Torrado, pronunció durante su inauguración, aclaraban que por su carácter internacional dicho congreso deseaba ejercer como escaparate de la Revolución al mundo. ${ }^{62}$ Las discusiones de las diferentes comisiones gira-

6o. Para Mosquera, esa buena recepción se vinculaba con la tradición vanguardista del arte cubano, que sin dejar de incorporar contenidos de carácter político-social, lo predisponía negativamente a la importación dogmática del realismo socialista. El crítico cubano era más precavido en su evaluación del concepto de "praxis-creadora", en la medida en que intuía en él los riesgos de una inercia productivista que pusiera en peligro la especificidad del lenguaje artístico, diluyéndola en la actividad genérica del hombre en las esferas productiva y reproductiva. Sin embargo, se felicitaba por el hecho de que Sánchez Vázquez nunca hubiera sucumbido a esa tentación. El elitismo conservador de esta posición modernista alertaba contra la inscripción sobre un mismo plano antropológico del trabajo no enajenado, la comprensión de la estética como teoría de la sensibilidad y la creación artística, en la medida en que tendía a disolver la particularidad de esta última y a amenazar su pervivencia mediante una proyección utópica que en el futuro aboliría su autonomía en la esfera social, véase Gerardo Mosquera, "Sánchez Vázquez: marxismo y arte abstracto”, en eds. Juliana González, Carlos Pereyra y Gabriel Vargas Lozano, Praxis y filosofía. Ensayos en homenaje a Adolfo Sánchez Vázquez (Ciudad de México: Grijalbo, 1985), 232-238.

6I. En opinión de este autor, lo valioso de la aportación de Sánchez Vázquez residiría en su concepción de la pintura "como un lenguaje multinivel con potencial dialógico, más que como una forma de imagen 'realista', realizada con una función dialéctica”, véase Craven, Art and Revolution in Latin America, I52-I53.

62. "Desde el escenario de los países imperialistas [...] se anunciaba siempre la necesidad de un esfuerzo por defender la libertad de la cultura y se acusa a los países en trance de construcción socialista o revolucionaria la ejecución de una política tendiente a frustrar esa llamada libertad de la cultura. Y este Congreso, por la composición de los delegados que en el mismo participan y la libertad dispuesta para los debates de la agenda, es la prueba más evidente de que constituye un verdadero ejercicio de libertad de la cultura”, en Congreso Cultural de La Habana. Reunión 
ron en torno a temas como la colonización intelectual derivada de la penetración cultural imperialista; la "tergiversación" sufrida por "la ideología de la negritud" al desgajarla de los procesos de liberación en que se había gestado; la posibilidad de concebir el marxismo como una "ciencia de la revolución"; la construcción de una nueva hegemonía cultural que en el plano nacional e internacional luchara "tanto contra los falsos valores de la cultura metropolitana como contra los estereotipos y mistificaciones de la cultura nacional"; la necesaria conjugación entre organización política, prácticas culturales y conciencia de clase como "fuerza revolucionaria del Tercer Mundo"; la reactivación de la figura pública del intelectual a partir de su presencia en los medios de comunicación; o la reconstitución de la ideología racista bajo la lógica del imperialismo capitalista, de modo que la desaparición de una y otra se encontraba íntimamente vinculada. ${ }^{63} \mathrm{La}$ Comisión V, en la que participó Sánchez Vázquez, divulgó una resolución en la que las relaciones entre la vanguardia política y la vanguardia artística oscilaban entre sus funciones detonadoras de un proceso revolucionario y su papel en la creación de un arte socialista y una cultura popular como aquel "hecho político" que, sin despreciar la tradición nacional, se proyectara en un plano internacionalista. Para concluir, la "Declaración general” expresaba el tono político-cultural de la época: puesto que la emergencia de toda verdadera cultura exigía acabar con el imperialismo, el acto artístico-cultural más valioso era la revolución. ${ }^{64}$

Como he relatado en otro lugar, estas ideas atravesaron también los argumentos de los encuentros de artistas que tuvieron lugar en Santiago de Chile y La Habana hasta la caída del gobierno de Allende. El deseo de dar forma a

de intelectuales de todo el mundo sobre problemas de Asia, África y América Latina (La Habana: Instituto del Libro, 1968), s. p.

63. Paula Barreiro ha inscrito las discusiones sostenidas durante el congreso en el contexto de la creación de diversos colectivos artísticos en el eje transatlántico de la guerra fría, y ha mostrado las sinergias entre los debates cubanos y la agitación sesentayochista en Francia (Paula Barreiro López, "Collectivization, Participation and Dissidence on the Transatlantic Axis During the Cold War: Cultural Guerrilla for Destabilizing the Balance of Power in the 196os", Culture \& History Digital Journal 4, núm. I (junio de 20I5): 8 y ss., consultado el 20 de junio de 20I7, en http://cultureandhistory.revistas.csic.es/index.php/cultureandhistory/article/viewArticle/7I/258.

64. "No se trata de formular una política cultural, sino de coincidir en la creación de condiciones en las que la producción artística pueda desarrollarse plenamente; y en consecuencia ir elaborando un hecho político que resulta de las necesidades de la creación misma”, Congreso Cultural de La Habana. Reunión de intelectuales de todo el mundo sobre problemas de Asia, África y América Latina (La Habana: Instituto del Libro, 1968), s. p. 
una cultura popular como expresión de un arte socialista no estaba exento de puntos ciegos. Con frecuencia, el concepto de cultura sobre el que se asentaba ese deseo definía la singularidad de la expresión popular de modo básicamente negativo, lo que impedía vislumbrar cuál sería la apariencia positiva que debería adquirir en el trabajo concreto desarrollado por los artistas en el seno de las organizaciones políticas. La negación de partida era la exclusión de todo signo sensible de ascendencia imperialista, que en el caso de los artistas que habían transitado los espacios y las formas de la vanguardia durante los años sesenta revelaba un cierto complejo de culpa por haber asumido un gusto estético extranjerizante. Pero, si cabe, resultaba aún más delicada la presuposición según la cual esas formas y estilos (pensemos, por ejemplo, en el arte pop) no se habían infiltrado ya en esa cultura popular cuya expresión primigenia, pura y anterior se pretendía, a partir del ejemplo cubano, contribuir a manifestar. En otro de los polos de la economía simbólica de esta posición estético-política se situaba el problema del folklore y el indigenismo, ante los cuales los artistas también mostraron reticencias a la hora de identificar en ellos la esencia de la cultura del pueblo. Finalmente, un tercer vértice evidenciaba la resistencia a oponer a la experimentación vanguardista un realismo naturalista que reprodujera nuevamente la fe en la transparencia pedagógica de esos signos. Ante esta triple obturación negativa de las posibilidades de articulación entre la práctica artística y la voluntad popular, parece lógico que muchos artistas coincidieran con el argentino Luis Felipe Noé al ceñir a la idea misma de revolución el horizonte inmediato del arte latinoamericano. ${ }^{65}$

En sintonía con ese clima de época, Sánchez Vázquez reconocía la posibilidad que la Revolución cubana había abierto para superar la oposición modernista entre el arte de vanguardia y el de masas. El intelectual hispano-mexicano compartía con los debates artísticos mencionados la necesidad de articular la experimentación con la inserción del cuerpo del artista en las luchas impulsadas por las organizaciones revolucionarias. ${ }^{66}$ Sin embargo, esa conjugación no debía trascender la autonomía del arte, que Sánchez Vázquez vinculaba con el carácter histórico-social de la experiencia de "apropiación estética" moderna. El filósofo no cuestionaba la estética como tal, sino una de las formas particu-

65. Jaime Vindel, La vida por asalto: arte, politica e historia en Argentina entre 1965 y 2001 (Madrid: Brumaria, 2014), I84-194.

66. Adolfo Sánchez Vázquez, "Vanguardia artística y vanguardia política", Casa de las Américas, núm. 47 (I968), II2-II5. 
lares de esa apropiación: la contemplación. La relación contemplativa con la obra de arte sería, en su opinión, un producto de la objetivación del trabajo creador, que pese a oponerse a la alienación impuesta por el modo de producción capitalista no debía perdurar en una sociedad socialista. En la medida en que la contemplación aparecía vinculada a la división del trabajo capitalista, aquélla debía dejar paso a una nueva forma de apropiación estética: la "socialización de la creación”. Ésta no debía renunciar a actualizar la herencia productivista en lo relativo a la síntesis entre arte, técnica y utilidad, pero Sánchez Vázquez se apresuraba a cuestionar como un gesto típicamente burgués la tendencia a confundir "la revolución en el arte, o contra el arte, con el arte de la revolución". ${ }^{67}$ La sintaxis entre estética y praxis, por tanto, negaba el capitalismo y conservaba la modernidad. La "praxis creadora" adquiría una dimensión antropológica que reafirmaba la autonomía del arte como poiesis (producción), antítesis activa de la pasividad y el eurocentrismo falsamente universalista de la experiencia contemplativa. La muerte del arte se identificaba, de este modo, con su renacer socializado. ${ }^{68}$

El relámpago histórico de la Revolución cubana permitió iluminar en Sánchez Vázquez sus recuerdos de la guerra civil española. Cuando el filósofo retornó a México tras el Congreso Cultural de La Habana de 1968, escribió un artículo para la revista Cuadernos Americanos en el que establecía una relación de afinidad entre el congreso cubano, al que asistieron más de 500 intelectuales de Asia, África y América Latina y las sesiones del II Congreso Internacional de Escritores Antifascistas celebradas tres décadas antes en Madrid (julio de 1937), a las que Sánchez Vázquez había acudido como director de la revis-

67. Adolfo Sánchez Vázquez, "Socialización de la creación o muerte del arte”, VII Congreso Internacional de Estética, Bucarest, 28 de agosto al 2 de septiembre, 1972, en Adolfo Sánchez Vázquez, De la estética de la recepción a una estética de la participación (Ciudad de México: Universidad Nacional Autónoma de México, 2005), II7.

68. Sánchez Vázquez insistiría más tarde en volver a articular praxis política y apropiación estética con la intención de distanciar a esta última de las consecuencias prácticas de la crítica posmoderna de la idea de "fundamento". La parálisis de la acción política revolucionaria derivada de dicha crítica habría privilegiado la contemplación como su correlato estético —o, más bien, esteticista: "el posmodernismo desplaza la atención de la acción a la contemplación, de lo político a lo estético. Pero, a su vez: de lo estético liberado de la tendencia moderna que cristalizó en la vanguardia originaria — futurismo, Prolet-Kult, productivismo, entre otros—-, a conjugar innovación artística e innovación social, arte y revolución, lo que introducía la emancipación en la entraña misma del arte", en Adolfo Sánchez Vázquez, "Posmodernidad, posmodernismo y socialismo", Casa de las Américas, núm. 175 (1989): 143. 
ta Ahora, órgano de expresión de las Juventudes Socialistas Unificadas (Jsu). ${ }^{69}$ Cargado de dosis románticas, el internacionalismo revolucionario hacía colisionar en el contexto de la guerra fría dos referentes simultáneos que quedaban de ese modo resignificados. Si la contienda espańola, en tanto preámbulo de la segunda guerra mundial, había concentrado las tensiones de los años treinta en la pugna entre fascismo y comunismo, la consolidación posterior de la política de bloques era cuestionada por el movimiento de los países no alineados, destinados a revitalizar las aspiraciones no cumplidas por los proyectos emancipatorios del pasado. La acción práctica de intelectuales y artistas debía deshacerse del colonialismo cultural y la intromisión imperialista en una perspectiva política que, si bien por entonces aún se centraba en el enemigo norteamericano, más tarde, tras la fallida primavera de Praga (1968), el propio Sánchez Vázquez extendería a la crítica radical del Estado burocrático soviético. ${ }^{70}$

Entretanto, el paulatino distanciamiento de los partidos comunistas occidentales respecto a Moscú allanaba el camino a la adopción de las tesis eurocomunistas. La apuesta democrática que esa opción entrańaba no siempre afectó a su organización interna, pero permitió relajar las ortodoxias teóricas que habían prevalecido en épocas anteriores. En ese intervalo temporal es posible constatar el interés que los textos de Sánchez Vázquez suscitaron entre la "crítica militante" situada al interior o en las proximidades del PCE dentro del territorio español. La formación subjetiva de esa crítica ha de ubicarse en la experiencia histórica de los sesenta, contexto en el que intelectuales, críticos y artistas se vieron convulsionados por las movilizaciones de obreros y estudiantes, al tiempo que tejían nuevas redes internacionales de contacto con colegas foráneos que les permitían resistir el aislamiento impuesto por la cultura de la dictadura. ${ }^{71}$ Las publicaciones de Sánchez Vázquez circularon clandestinamente en los ańos del tardofranquismo, incorporándose a un espacio común de debate que contó con otras aportaciones valiosas. Las discusiones relativas a la

69. Adolfo Sánchez Vázquez, "Dos impresiones sobre el Congreso Cultural de La Habana”, Cuadernos Americanos 158, núm. 3 (1968): 53-60.

70. Adolfo Sánchez Vázquez, "Ideal socialista y socialismo real”, Simposio Internacional "Del socialismo existente al nuevo socialismo", Caracas, del 27 al 3I de mayo, 198I, en Adolfo Sánchez Vázquez, Entre la realidad y la utopía. Ensayos sobre política, moral y socialismo (México: Fondo de Cultura Económica/Universidad Nacional Autónoma de México-Facultad de Filosofía y Letras, I999), IOI-I22.

71. Paula Barreiro López, Avant-garde Art and Criticism in Francoist Spain (Liverpool: University Press, 20I7), I2I-292. 
filosofía de la praxis habían sido detonadas por la recuperación teórica que de la obra de Gramsci realizó Manuel Sacristán. Tras la publicación de su artículo "La formación del marxismo de Gramsci", aparecido en 1967 en el número I4 de Realidad, Sacristán compilaría y traduciría una Antología de textos del pensador corso. El volumen, que se convertiría en una lectura de referencia para la cultura española de izquierdas de la década, se publicó por primera vez en México en 1970 en la colección de Siglo XXI. Las dificultades para la difusión de estas ideas en el Estado español se evidencian en la respuesta negativa que por su parte sufrió la editorial Grijalbo cuando en 1972 trató de publicar una nueva edición de Filosofía de la praxis, el libro de Sánchez Vázquez que cité más arriba. Dos de los censores del Ministerio de Información y Turismo no autorizaron un escrito en el que entreveían la amenaza que una interpretación no estrictamente erudita del pensamiento de Marx implicaba para el trance político del tardofranquismo..$^{72}$

La filosofía de la praxis de Sánchez Vázquez, aún heredera de la matriz leninista, así como su recomposición gramsciana a través de la mirada de Sacristán, encontraron su correlato en el campo del arte español de ese periodo en la actividad editorial del Equipo Comunicación, integrado por Alberto Corazón, Miguel García Sánchez, Alberto Méndez, Juan A. Méndez y Valeriano Bozal. Corazón y Bozal conocieron a Sánchez Vázquez en 1972 en Madrid, durante el primer viaje que el filósofo hispano-mexicano realizó a España tras

72. AGA, caja (3) 50 73/02482, exp. I2743. De las tres opiniones vertidas, dos denegaban el permiso de publicación. Para el primero de los censores, el libro, "más que investigación" era "una guía práctica con fines de enseñanza y propaganda [...] una afirmación sin restricciones de las prácticas comunistas [...] como la única verdad de la historia”. El segundo, por su parte, recalcaba que pese a que la obra no era panfletaria, se encontraba inspirada por una "mente marxista, al igual que las obras de Althusser o Garaudy”, dos autores con los que Sánchez Vázquez mantenía una desigual afinidad. Mejor suerte corrió su Ética, que, pese a su transversalidad crítica y a su inscripción histórico-contextual, mereció el siguiente comentario del censor: "Se trata de un manual de ética en el que el autor estudia sistemáticamente todas las implicaciones en torno a esta ciencia. Ve su esencia, la diferencia ético-moral, su objeto, sus relaciones con otras pautas de realización del hombre (política, religión, etc.), la valoración de lo ético, la responsabilidad moral, etc., etc. Las líneas fundamentales con que define lo ético corresponden a la interpretación cristiana y escolástica. En este sentido nos parece una obra de divulgación perfectamente autorizable y puede ser útil, pues es una exposición bien hecha, clara y positiva”. El comentario aparece firmado por "Morán", apellido de Pedro Borges Morán, miembro de la "Plantilla de lectores fijos de la sección de ordenación editorial", con "estudios eclesiásticos e idiomas". AGA, caja (3) 50 73/02482, exp. 12744-72. 
su exilio posterior a la guerra civil. ${ }^{73}$ En el segundo de los viajes, organizado en 1976, Bozal entrevistaría a Sánchez Vázquez para la revista Triunfo. Uno de los temas abordados en la entrevista giró en torno a las relaciones entre historia y estructura a partir de la consideración crítica de las tesis de Althusser. ${ }^{74}$ Esa línea de trabajo había atravesado desde su fundación el proyecto de Comunicación, preocupado a finales de los sesenta por la parálisis política que cierta lectura del estructuralismo estaba ocasionando en los entornos universitarios del tardofranquismo. ${ }^{75}$ Sánchez Vázquez, por su parte, había propuesto en el artículo publicado por la Casa de las Américas una particular síntesis entre el legado guevarista y la obra de Althusser al abogar por un modelo de "historia estructural" que evitara tanto sobrevalorar el papel de los sujetos en el devenir histórico como la fetichización de las estructuras. ${ }^{76}$ Se trataba, en el fondo, de dar forma a un proyecto teórico que abogaba por aunar al primer y último Marx, el filósofo de la praxis y el crítico de la economía política clásica, contra las pretensiones cientificistas del corte epistemológico. ${ }^{77}$

73. Valeriano Bozal, "Compañero de viaje”, La Balsa de la Medusa, núm. 50 (1999): 74.

74. Valeriano Bozal, "Adolfo Sánchez Vázquez: de este tiempo, de este país”, Triunfo, año 2I, vol. 7, núm. 6 (1976): 36-39.

75. Valeriano Bozal, El intelectual colectivo y el pueblo (Madrid: Alberto Corazón, 1976).

76. Sánchez Vázquez, "Estructuralismo e historia”, 3I-43.

77. Al margen de la disputa epocal entre las variantes praxeológica y estructuralista del marxismo, Santiago Castro Gómez ha acusado a Sánchez Vázquez desde posiciones próximas a la teoría poscolonial de formar parte de aquel conjunto de pensadores latinoamericanos que, pese a plantear una contranarrativa de la modernidad, no consiguen salir de la episteme delimitada por la filosofía de la historia de Hegel. Para Castro Gómez, la filosofía de la praxis de Sánchez Vázquez y la filosofía de la liberación de Enrique Dussel compartirían una matriz romántica y voluntarista cuya ascendencia se remontaría a la obra del filósofo mexicano Leopoldo Zea, inspirado por el pensador alemán (Santiago Castro Gómez, Crítica de la razón latinoamericana [Barcelona: Puvill Libros, I996], II-I8). Zea fue discípulo del filósofo español José Gaos, a cuyas clases también asistió Sánchez Vázquez. Aunque es evidente que ese voluntarismo praxeológico no es ajeno a la obra de Sánchez Vázquez, siempre aparece tensionado de manera dialéctica. En este plano, es interesante contrastar la crítica de Castro Gómez con la valoración que el filósofo hispano-mexicano realizó respecto a la necesidad de reinventar el proyecto socialista en el contexto de los debates suscitados por la posmodernidad. Para Sánchez Vázquez, se trataba de "contribuir a fundar, esclarecer y guiar la realización de ese proyecto de emancipación que, en las condiciones posmodernas, sigue siendo el socialismo — un socialismo si se quiere posmoderno-, sólo puede hacerse en la medida en que la teoría de la realidad que hay que transformar y de las posibilidades y medios para transformarla, esté atenta a los latidos de esa realidad y se libere de las condiciones teleológicas, progresistas, productivistas y eurocentristas de la modernidad que llegaron incluso a impregnar el pensamiento de Marx y que se han prolongado en nuestro tiempo. Lo cual significa a su vez que 
En el campo de la estética, las cuestiones planteadas por Sánchez Vázquez en torno al Marx de los Manuscritos esbozaban una orientación teórica común a la delineada a principios de la década de los setenta por el esteta español Simón Marchán Fiz, cuando éste se aproximó a aquellas experiencias del arte conceptual internacional que se situaban más allá de las formulaciones tautológicas. La referencia bibliográfica específica a la obra del filósofo hispano-mexicano se halla en un texto de finales de los años setenta, titulado "La utopía estética en Marx y las vanguardias históricas", donde Marchán Fiz diagramaba, con tono un tanto crepuscular afín a los primeros desencantos de la Transición, un análisis retrospectivo de las antinomias de ese proyecto artístico. La matriz conceptual del ensayo, publicado en el volumen colectivo El descrédito de las vanguardias artísticas (1980), identificaba el contenido utópico de éstas en su concepción ampliada de la estética como una teoría de la sensibilidad. ${ }^{7}$ Sin embargo, la comprensión antropológica del potencial emancipatorio de las vanguardias artísticas se puede rastrear ya en la caracterización que el propio Marchán Fiz realizara del "conceptualismo ideológico" en la segunda edición de su libro Del arte objetual al arte de concepto (I960-1974). Quizá no se haya destacado suficientemente el orden en el despliegue de los contenidos del libro, en el que este capítulo se intercalaba entre, por un lado, el análisis conceptual lingüístico, tautológico y empírico-medial y, por otro, su "inversión” praxeológica en los "nuevos comportamientos artísticos" del conceptualismo español. Pese a que la información de la que disponía el historiador español era fragmentaria, es muy notable el esfuerzo por abrir una vía que triangulara teóricamente las noticias que tenía relativas al itinerario de la vanguardia argentina de los años sesenta (así como del CAYC, el Centro de Arte y Comunicación de Buenos Aires, dirigido por el empresario Jorge Glusberg), la eclosión del arte conceptual en España y las experiencias del Guerrilla Action Group en Estados Unidos. Cuando consideraba las posibilidades de que el conceptualismo bascu-

no hay que echar en saco roto las críticas de la modernidad después de Marx, ni lo que la crítica del posmodernismo aporta — sin proponérselo- a esa emancipación” (Adolfo Sánchez Vázquez, "Posmodernidad, posmodernismo y socialismo", Casa de las Américas, núm. I75 (I989): I45. Las precauciones contra los restos hegelianos en el marxismo afloran aquí como una demostración de la capacidad autocrítica de Sánchez Vázquez a la hora de reformular sus posiciones e incorporar de modo dialéctico incluso las aportaciones de aquellas tendencias filosóficas que podían resultar antitéticas en relación con el materialismo histórico.

78. Simón Marchán Fiz, "La utopía estética en Marx y las vanguardias históricas", en Victoria Combalía Dexeus, coord., El descrédito de las vanguardias artísticas (Barcelona: Blume, 1980), 9-45. 
lara de ser una fuerza productiva a convertirse en una fuerza social, Marchán Fiz acuñaba una fórmula que remite a la aleación entre praxis y estética del pensamiento marxiano. Al convertirse "en uno de los modos específicos de la apropiación práctica de la realidad" (la similitud con la estética no contemplativa de Sánchez Vázquez es evidente), el arte experimental debía superar las insuficiencias del realismo crítico tradicional y recuperar "una instancia antropológi$c a$ " (cursiva en el original) que fundara "una teoría emancipatoria enfrentada a los comportamientos configurados por la actual práctica social”. El proceso de movilización que de ello se derivara debía evitar cualquier forma de conformismo, al oponer "una estrategia de comportamiento perceptivo-cognoscitivo y creativo, a nivel individual y social, de y sobre la realidad". Este enfoque permite recomponer la imagen de los nuevos comportamientos que el autor comenzaba a analizar apenas unas líneas después. En los tres párrafos que cerraban el bloque teórico de las prácticas conceptuales situadas "más allá de la tautología”, Marchán Fiz manejaba dos referentes de la obra del primer Marx, sin declarar su uso de manera explícita. En una alusión directa al modo en que el filósofo de Tréveris analizara en los Manuscritos los sentidos humanos como una acumulación de la experiencia a lo largo de la historia universal, Marchán subrayaba que aquéllos "no son algo abstracto, originario, sino órgano social de apropiación del mundo". Y más adelante retornaba sobre La ideología alemana (I845) para prevenir de un sociologismo de los contenidos que despreciara la reflexión sobre la ideología implícita en los medios de comunicación; una inclinación que identificaba el sector más propagandista del conceptualismo ideológico. Marchán Fiz mencionaba como ejemplo de resistencia a esa inercia la exposición Leer la imagen, de Alberto Corazón, que se mostró en sucesivas versiones entre 1971 y 1972 en la Galería Redor de Madrid y el Colegio de Arquitectos de Barcelona. ${ }^{79}$

La única referencia de Marx y Engels que figuraba entre la bibliografía del libro de Marchán Fiz, en la sección relativa a "Cuestiones de teoría y lenguaje artístico", era Textos sobre la producción artística, una compilación de octubre de 1972 con las aportaciones sobre esa cuestión de los fundadores del materialismo histórico. El volumen integró la serie B de la colección de títulos impulsada por el equipo Comunicación y auspiciada por la editorial del propio Corazón. Ese mismo año había aparecido en la colección la primera edición puede consultarse en Alberto Corazón, Aire, fuego, tierra, agua (Madrid: La Fábrica, 2007). 
Del arte objetual al arte de concepto (1972), cuya segunda edición Marchán Fiz dedicaría en 1974 por partida doble al artista (Corazón se ocupaba además del diseño de las publicaciones) y al equipo madrileños. ${ }^{80}$ El apartado de Textos sobre la producción artística centrado en las "Cuestiones de historia y crítica" se abría con varios extractos de los Manuscritos, correspondientes a la primera traducción realizada por Wenceslao Roces en 1962 para su publicación en México por la editorial Grijalbo y posteriormente difundida por la editorial Política en La Habana (1965). Esta última era la edición recuperada por la compilación de Comunicación y, no por casualidad, el fragmento reproducía los pasajes que inspiraron en 1974 la conceptualización de Marchán Fiz de los nuevos comportamientos artísticos. ${ }^{8 \mathrm{I}} \mathrm{La}$ introducción al volumen de Marx y Engels llevaba la firma de Valeriano Bozal, quien se congratulaba de un hecho que para la tradición estética marxista había sido tradicionalmente un problema: el carácter fragmentario de los textos sobre arte y literatura alumbrados por ambos autores. Los beneficios de esa inorganicidad reflexiva eran el mejor antídoto "contra el dogmatismo que dominó en el pensamiento marxista en los años anteriores e inmediatamente posteriores a la segunda guerra mundial", pues impidió "ver la estética como campo cerrado y hecho". ${ }^{82}$ El papel que los debates estéticos tuvieron en los entornos culturales del PCE lo reflejaba Bozal cuando afirmaba que "la estética fue uno de esos horizontes abiertos donde muchas veces se han debatido cuestiones que bien poco tenían que ver con los problemas estéticos en sí mismos". ${ }^{83}$ A la hora de constatar el carácter "abierto y polémico de la estética" citaba como prueba "la reciente antología de A. Sánchez Vázquez, en la que se recogen las principales aportaciones sobre el particular" ${ }^{84}$ Estas palabras enviaban un modesto guiño al filósofo hispano-mexicano, mucho más ambicioso al incluir en su estudio las aportaciones de autores marxistas procedentes de múltiples contextos geográficos y temporales. ${ }^{85} \mathrm{Al}$ refractar la

80. Simón Marchán Fiz, Del arte objetual al arte de concepto (I960-1974) (Madrid: Alberto Corazón, 1974), 326-329.

8I. Karl Marx y Friedrich Engels, Textos sobre la producción artística (Madrid: Alberto Corazón, I972), I05-I08.

82. Valeriano Bozal, introd. a Karl Marx y Friedrich Engels, Textos sobre la producción artística (Madrid: Alberto Corazón, 1972), ıо.

83. Bozal, Textos sobre la producción.

84. Bozal, Textos sobre la producción.

85. Al margen de la antología sobre Estética y marxismo de Sánchez Vázquez (Adolfo Sánchez Vázquez, Estética y marxismo, t. I y II [México: Era, 1970]), el volumen de Comunicación señalaba como un hito precedente la recopilación de textos Sobre arte y literatura que había publicado 
producción de un sector del comunismo antifranquista a través del prisma de algunas de las incursiones teóricas de Sánchez Vázquez durante los años sesenta, es posible atisbar una zona de la crítica militante de la Espańa del tardofranquismo desde una mirada que salva el abismo de las relaciones norte-sur en la historia del pensamiento estético. Ese ángulo de enfoque puede incluso promover una inversión en el sentido de su comprensión, al reinscribir los planteamientos críticos de la época en el espacio intersticial situado entre el influjo de la producción teórica que acompañó a los procesos revolucionarios de la América (pos)colonial y el faro de homologación de la modernidad europea.

\section{Epigrafe}

En una serie de conferencias pronunciadas en la Universidad de California durante la década de los ochenta, posteriormente recogidas bajo el título In the Tracks of Historical Materialism (1983), Perry Anderson hacía balance de las predicciones que él mismo había realizado al final de Considerations on Western Marxism sobre la posible orientación futura del materialismo histórico. Anderson se lamentaba del declive del marxismo latino frente al repunte de los estudios materialistas procedentes del eje transatlántico anglosajón. Las razones de ese declive se circunscribían, según el intelectual inglés, a dos motivos. El primero de ellos era el fracaso o el alcance relativo de los procesos históricos de ruptura con las dictaduras en países del sur de Europa como Portugal, España o Grecia. El segundo, los límites intrínsecos a la vía eurocomunista al socialismo, enfangada en el "compromiso histórico" incentivado por la dirección del Partido Comunista Italiano a finales de la década de los setenta. ${ }^{86}$ Aunque tal generalización ensombrecía el abanico de posiciones que la producción teórica

en 1968 Ciencia Nueva, también prologados y seleccionados por Bozal. En esa publicación, que reconocía su familiaridad con las ediciones publicadas antes en Buenos Aires y La Habana en 1964 y 1965 , se encuentra la primera resonancia escrita en el mundo editorial español de Las ideas estéticas de Marx: se trata, en particular, de un pasaje en el que Bozal destaca la lectura no sociologista que Sánchez Vázquez había realizado de las tesis de Lenin en torno a la obra de Tolstoi (Marx y Engels, Sobre arte y literatura, 39-40). Para el filósofo hispano-mexicano, esos artículos superaban las limitaciones que se podían derivar de la aplicación mecánica al ámbito de la estética de la teoría del reflejo que el propio Lenin había diagramado en Materialismo y empiriocriticismo (1909), situándose a distancia de las inclinaciones tanto subjetivistas como objetivistas en que habrían caído autores como Lafargue, Mehring o Plejanov.

86. Perry Anderson, In the Tracks of Historical Materialism (Londres: Verso, 1983). 
marxista alumbró durante el periodo en geografías como la italiana, es cierto que en el caso español el modo en que se decantó el cierre transicional sí que comprometió la pervivencia de un marxismo renovado que se tradujera en proyectos políticos con una orientación disruptiva. Sánchez Vázquez, por su parte, decidió permanecer en México tras el retorno de la democracia. Su trabajo posterior persistió en la crítica de las estructuras teóricas e históricas del marxismo ortodoxo y del socialismo real, pero sin renunciar nunca - incluso durante la larga noche neoliberal de los noventa - a actualizar de modo creativo el pensamiento marxiano. Queda para otro momento dilucidar críticamente el modo en que la trayectoria de Sánchez Vázquez convoca en una imagen dialéctica la historia del comunismo español del siglo xx, el exilio de la modernidad eurocentrada, los espectros de Marx y las epistemologías del sur. En todo caso el "minúsculo recuerdo de una infinita subjetividad" 87 constelado por la memoria de su figura aún puede iluminar el tiempo presente, al descentrar y conjugar a ambos lados del Atlántico los conceptos de comunismo y de sur en una nueva dimensión emancipadora. \$

87. Así lo recordaba Enrique Dussel en el seminario de homenaje que la Universidad Nacional Autónoma de México dedicó a Sánchez Vázquez tras su muerte en 20 Ir (Enrique Dussel, Filosofías del sur. Descolonización y transmodernidad [México: Akal, 2015, 247-254]). A propósito de la posibilidad de establecer un diálogo entre ambos autores, una de las aportaciones centrales de la obra de Sánchez Vázquez reside en su análisis de las relaciones de poder a partir de una mirada que, en sucesivas etapas, abarcó la actualización del leninismo, la deconstrucción histórico-conceptual del socialismo de Estado o, incluso, la crítica democrática del concepto gramsciano de hegemonía. La pulsión praxeológica de ese trabajo intelectual no debería ser desmerecida por los autores situados en la órbita de la filosofía de la liberación o del pensamiento decolonial, a menudo más inclinados a enfatizar las discusiones de índole epistemológica.

N.B. Este trabajo ha sido realizado gracias a la Ayuda Juan de la Cierva-Incorporación 2015 concedida por el Ministerio de Economía, Industria y Competitividad del Gobierno de España y como parte de los proyectos de investigación en los que participa el autor: "Visualidades críticas: reescritura de las narrativas a través de las imágenes" (HAR2013-430r6-P) y "Modernidade(s) descentralizada(s): arte, política y contracultura en el eje trasatlántico durante la guerra fría" (HAR2OI4-53834-P). 